\title{
Angiotensin II Activation of mTOR Results in Tubulointerstitial Fibrosis through Loss of $\mathrm{N}$-Cadherin
}

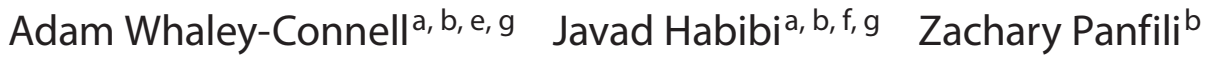 \\ Melvin R. Hayden b, f, g Sarika Bagree ${ }^{\text {b, g }}$ Ravi Nistalab,e,g Safwan Hyder ${ }^{\text {b, g }}$ \\ Bennett Krueger ${ }^{b, g}$ Vincent DeMarco ${ }^{b, c, f, g}$ Lakshmi Pulakat $^{\text {b, } d-g}$ \\ Carlos M. Ferrario $^{h} \quad$ Alan Parrish $^{c, e}, f \quad$ James R. Sowers ${ }^{a-c, f, g}$ \\ ${ }^{a}$ Harry S. Truman VA Medical Center, and the University of Missouri-Columbia School of Medicine, Departments of \\ ${ }^{b}$ Internal Medicine, ${ }^{C}$ Medical Pharmacology and Physiology, ${ }^{d}$ Nutrition and Exercise Physiology, Divisions of \\ ${ }^{\mathrm{e}}$ Nephrology and ${ }^{\mathrm{f}}$ Endocrinology, and the ${ }^{\mathrm{g}}$ Diabetes Cardiovascular Center, Columbia, Mo., and ${ }^{\mathrm{h}}$ Hypertension \\ and Vascular Disease Unit, Wake Forest University, Winston-Salem, N.C., USA
}

\section{Key Words}

Angiotensin II $\cdot \mathrm{mTOR} \cdot \mathrm{N}$-Cadherin $\cdot$ Proximal tubule $\cdot$

Tubulointerstitial fibrosis

\begin{abstract}
Background/Aims: Angiotensin (Ang) II contributes to tubulointerstitial fibrosis. Recent data highlight mammalian target of rapamycin (mTOR)/S6 kinase 1 (S6K1) signaling in tubulointerstitial fibrosis; however, the mechanisms remain unclear. Thereby, we investigated the role of Ang II on mTOR/ S6K1-dependent proximal tubule (PT) injury, remodeling, and fibrosis. Methods: We utilized young transgenic Ren2 rats (R2-T) and Sprague-Dawley rats (SD-T) treated with the Ang type 1 receptor $\left(A T_{1} R\right)$ blocker telmisartan $\left(2 \mathrm{mg} \cdot \mathrm{kg}^{-1}\right.$. day $^{-1}$ ) or vehicle (R2-C; SD-C) for 3 weeks to examine PT structure and function. Results: Ren2 rats displayed increased systolic blood pressure, proteinuria and increased PT oxidant stress and remodeling. There were parallel increases in kidney injury molecule-1 and reductions in neprilysin and megalin with associated ultrastructural findings of decreased clathrin-coated pits, endosomes, and vacuoles.
\end{abstract}

Ren2 rats displayed increased Serine ${ }^{2448}$ phosphorylation of mTOR and downstream S6K1, in concert with ultrastructural basement membrane thickening, tubulointerstitial fibrosis and loss of the adhesion molecule $\mathrm{N}$-cadherin. Telmisartan treatment attenuated proteinuria as well as the biochemical and tubulointerstitial structural abnormalities seen in the Ren 2 rats. Conclusions: Our observations suggest that Ang Il activation of the $\mathrm{AT}_{1} \mathrm{R}$ contributes to $\mathrm{PT}$ brush border injury and remodeling, in part, due to enhanced mTOR/S6K1 signaling which promotes tubulointerstitial fibrosis through loss of $\mathrm{N}$-cadherin.

Copyright $\odot 2011$ S. Karger AG, Basel

\section{Introduction}

In the development of chronic kidney disease, progressive tubulointerstitial fibrosis contributes to declining kidney function $[1,2]$. There is accumulating evi-

A. Whaley-Connell and J. Habibi contributed equally to the paper.

\section{KARGER}

๑ 2011 S. Karger AG, Basel

Fax +41613061234 E-Mail karger@karger.ch www.karger.com www.karger.com/ajn
Adam Whaley-Connell, DO, MSPH

Harry S. Truman VA Medical Center

800 Hospital Dr

Columbia, MO 65211 (USA)

Tel. +1 573814 6000, ext. 53729, E-Mail whaleyconnella@ health.missouri.edu 
dence that activation of the kidney renin-angiotensin system (RAS) and associated increases in oxidative stress are important instigators for proximal tubule cell (PTC) injury, structural remodeling, and tubulointerstitial fibrosis that contribute to progressive kidney disease [3-6]. Indeed, angiotensin (Ang) II signaling through the Ang type 1 receptor $\left(\mathrm{AT}_{1} \mathrm{R}\right)$ induces tubulointerstitial fibrosis by downregulating E-cadherin (an epithelial phenotype marker) while upregulating alpha-smooth muscle actin and other mesenchymal markers in epithelial-mesynchymal transition (EMT) [7, 8]. Blockade of Ang II signaling through the $\mathrm{AT}_{1} \mathrm{R}$ attenuates the progression of kidney disease in preclinical as well as clinical studies $[9,10]$. However, the role of the renal RAS in eliciting these early changes and the reversibility of the process with $\mathrm{AT}_{1} \mathrm{R}$ blockade remain unclear.

Recent data support a role for $\mathrm{AT}_{1} \mathrm{R}$ signaling in promotion of fibrosis in coronary smooth muscle cells, cardiac tissue, and skeletal muscle through activation of the mammalian target of rapamycin (mTOR)/S6 kinase 1 (S6K1) signaling pathway [11-13]. mTOR is a serine (Ser)/ threonine (Thr) kinase that regulates transcription and protein synthesis, cell growth, proliferation, and cell phenotype transition. In studies involving cardiomyocytes and mesangial cells, blockade of the $\mathrm{AT}_{1} \mathrm{R}$ may lead to reductions in $\mathrm{mTOR}$ signaling by targeting pathways that lead to reductions in NADPH oxidase subunits [13-15]. Furthermore, Ang II actions on the $\mathrm{AT}_{1} \mathrm{R}$ contribute to PTC injury through NADPH oxidase generation of oxidative stress $[16,17]$. Collectively, these data suggest a role for Ang II in injury to the proximal tubule (PT) and fibrosis through similar mechanisms that engage the mTOR/S6K1 pathway.

Data from models of diabetic and polycystic kidney disease indicate that targeting reductions in mTOR activity attenuates the progression of tubulointerstitial fibrosis [18-20]. The improvements in fibrosis following mTOR inhibition with rapamycin have been shown to be related to reductions in phosphorylation of S6K1. Recent evidence in carcinogenic models further suggests that increased mTOR/S6K1 signaling promotes loss of adherens junction markers and increased fibrosis [18, 21]. The catenin-cadherin complex is integral in cell-cell adhesion, and loss of cadherins is a critical first step in development of tubulointerstitial fibrosis and EMT [22-24]. Recent data support the importance of loss of PT-specific $\mathrm{N}$-cadherin in promotion of tubulointerstitial fibrosis [23]. However, our understanding of agonists that elicit loss of adhesion is limited in tubulointerstitial fibrosis and progressive kidney disease.
Accordingly, we hypothesized that Ang II contributes to PTC injury through oxidative stress, the mTOR/S6K1 pathway, and associated loss of $\mathrm{N}$-cadherin thereby promoting tubulointerstitial fibrosis. To ascertain the impact of Ang II signaling through the $\mathrm{AT}_{1} \mathrm{R}$ on $\mathrm{PT}$ injury and promotion of tubulointerstitial fibrosis, we examined structural and functional properties of the PT in relation to oxidant stress, mTOR/S6K1, and the PT-specific adhesion molecule $\mathrm{N}$-cadherin in the transgenic (mRen2)27 (Ren2) rats, a model that manifests elevated tissue Ang II and PTC injury related proteinuria $[16,25]$ treated with the $\mathrm{AT}_{1} \mathrm{R}$ blocker telmisartan.

\section{Animals and Methods}

Animals and Treatments

All animal procedures were approved in advance by the Harry S. Truman Veterans Memorial Hospital Subcommittee for Animal Safety, as well as by the University of Missouri IACUC, and animals were cared for in accordance with NIH guidelines. Fiveweek-old male heterozygous transgenic Ren2 ( $\mathrm{n}=12)$ and Sprague-Dawley (SD) littermates $(n=12)$ were housed under standard laboratory conditions. Rats were randomly distributed into the following groups: $\mathrm{SD}$ control (SD-C) $\mathrm{n}=6$, telmisartantreated SD (SD-T) $\mathrm{n}=6$, Ren2 control $(\mathrm{R} 2-\mathrm{C}) \mathrm{n}=6$, and telmisartan-treated Ren2 (R2-T) $n=6$. Beginning at 7 weeks of age, treated rats received daily telmisartan $(2 \mathrm{mg} / \mathrm{kg})$ or vehicle solution in drinking water for a total of 21 days [26].

\section{Metabolic Parameters}

Systolic Blood Pressure. Systolic blood pressures (SBPs) were obtained on a subset of rats previously reported [26]. At 6 weeks of age, rats were anesthetized and instrumented with a radio telemetric transmitter (TA11PA-C40; Data Sciences, St. Paul, Minn., USA) for blood pressure monitoring. Rats recovered a minimum of 7 days before data collection. Recordings of SBP were obtained at $0,1,2$, and 3 weeks post-treatment initiation. For each week, data were recorded continuously for $5 \mathrm{~min}$ at 15-minute intervals (sampling rate: $1,000 \mathrm{~Hz}$ ) for 3 light and 3 dark 12-hour cycles.

Urine Measures. Both creatinine and protein concentrations in urine were analyzed on an automated clinical chemistry analyzer (Olympus AU680) using commercial assays [16, 25]. Creatinine was determined using an automated Jaffe reaction assay and urine protein using an automated colorimetric assay.

Transmission Electron Microscopy

Renal cortical tissue was thinly sliced and placed immediately in primary transmission electron microscopy (TEM) fixative as previously described $[16,25]$. Sections $(85-\mathrm{nm})$ were stained with $5 \%$ uranyl acetate, and Sato's triple-lead stain and a TEM (model JEM 1400; Joel, LTD., Tokyo, Japan) were utilized. To maintain uniformity, we examined S-1 segments of the PT ( $n=4$ per group) with identifiable microvilli that were immediately adjacent to the glomeruli. 


\section{Immunohistochemistry}

Kidney cortical tissue was harvested and prepared as previously described [16]. Briefly, 4- $\mu \mathrm{m}$ sections were incubated with primary antibodies overnight at room temperature. Then slides were washed and incubated with 1:300 secondary antibodies for $4 \mathrm{~h}$, and the images were captured with a bi-photon confocal laser scanning microscope. Images were captured by LSM imaging system and signal intensities quantified by MetaVue as average gray scale intensities.

NADPH Oxidase Activity. NADPH oxidase activity was determined in kidney cortical tissue as previously described [16, 25]. Briefly, NADPH oxidase activity was determined by measuring the conversion of radical detector using spectrophotometry (450 nm).

3-Nitrotyrosine. Briefly, 4- $\mu \mathrm{m}$ kidney sections were incubated with 1:150 primary rabbit polyclonal anti-nitrotyrosine antibody overnight (Chemicon, Temecula, Calif., USA) as previously described $[16,25]$. Sections were then washed and incubated with secondary antibodies, biotinylated linked, and Streptavidin-HRP for $30 \mathrm{~min}$ each. After several rinses with Tris-buffered saline Tween-20 (TBST), diaminobenzidine was applied for $8 \mathrm{~min}$, sections rinsed several times with distilled water, and counterstained with hematoxylin for $80 \mathrm{~s}$, dehydrated, and mounted with a permount. The slides were inspected under a bright-field (Nikon 50i) microscope, the $\times 40$ images captured with a Cool Snapcf camera, and signal intensities quantified by MetaVue.

\section{Western Blot Analysis}

Sodium dodecyl sulfate polyacrylamide gel electrophoresis (SDS-PAGE) was performed on kidney homogenates. Samples (40 $\mu \mathrm{g} / \mathrm{lane}$ ) were separated and transferred to polyvinylidene difluoride membranes. Blots were blocked with 5\% BSA for $3 \mathrm{~h}$ and then washed briefly in TBST and incubated overnight at $4{ }^{\circ} \mathrm{C}$ with the following primary antibodies: S6K1, kidney injury molecule-1 (KIM-1), N-cadherin, and neprilysin (1:1,000 dilution; Cell Signaling Technology, Inc.). After rinsing, blots were incubated with horseradish peroxidase-conjugated secondary antibodies (1:10,000, Jackson Immunoresearch) for $1 \mathrm{~h}$ at room temperature. The bands were visualized by chemiluminescence, and images were recorded using a Bio-Rad image analysis system. The quantified proteins were normalized to the density of total protein for each sample as determined by amido black, performed using Quantity One software.

\section{Light Microscopic Analysis of Tubulointerstitial Fibrosis}

Five-microns thick paraffin sections were mounted on glass slides and stained with Verhoeff-Van Gieson (VVG) stain, which stains collagen fibers pink, to evaluate interstitial fibrosis, as previously described $[16,25]$. The relative amount of collagen within 10 representative regions of interest was determined with the aid of MetaVue Software and an average value was recorded for each kidney sample and expressed as arbitrary units. Samples from 5 rats from each of the 6 treatment groups were analyzed.

\section{Statistical Analysis}

This investigation was powered based on prior sensitivity and variability measurements of non-log transformed proteinuria to achieve a significance of $\mathrm{p}<0.05$ with a power of $0.8[16,25]$. All values are expressed as mean \pm standard error. Statistical analyses were performed in SPSS 13.0 (SPSS Inc., Chicago, Ill., USA) using ANOVA with Fisher's LSD as appropriate.

\section{Results}

\section{Ang II Contributes to Elevations in SBP and}

Proteinuria in the Transgenic Ren2 Rat

As reported elsewhere [26], there were increases in SBP in the Ren 2 rats compared to age-matched SD controls, findings were prevented following 3 weeks of treatment with the $\mathrm{AT}_{1} \mathrm{R}$ blocker telmisartan in the Ren 2 rats. There were parallel increases in non-log transformed proteinuria in the Ren 2 rats $(4.83 \pm 0.64 \mathrm{mg} / \mathrm{mg}$ urine protein/creatinine) compared to SD controls (1.68 \pm $0.29 \mathrm{mg} / \mathrm{mg} ; \mathrm{p}<0.05)$, and improvement was observed with telmisartan treatment $(2.77 \pm 0.18 \mathrm{mg} / \mathrm{mg} ; \mathrm{p}<$ 0.05).

\section{Ang II Contributes to PTC Oxidative Stress through Activation of the $A T_{1} R$ in the Transgenic Ren2 Rat}

Ang II activation of the $\mathrm{AT}_{1} \mathrm{R}$ has been implicated in development and progression of kidney disease through increases in oxidant stress and pro-inflammatory mechanisms [27-29]. In this regard, semi-quantitative immunohistochemical analysis showed increased density of PT $\mathrm{AT}_{1} \mathrm{R}$ in the Ren 2 rats compared to SD controls. Telmisartan treatment resulted in reduced expression of $\mathrm{AT}_{1} \mathrm{R}$ in Ren2-treated rats (fig. 1a). In parallel with the increases in $\mathrm{AT}_{1} \mathrm{R}$ receptor expression, there were increases in 3-nitrotyrosine (3-NT), a marker for peroxynitrite $\left(\mathrm{ONOO}^{-}\right)$formation in Ren2 rats $[16,25] . \mathrm{ONOO}^{-}$is a highly reactive oxidant species that can be formed endogenously by the interaction of nitric oxide (NO) and superoxide anion $\left(\mathrm{O}_{2}{ }^{-}\right)$, and this product reacts readily with tyrosine residues of proteins to form 3-NT. Renal cortical PT 3-NT content was higher in the Ren2 rats compared to SD controls, findings improved with telmisartan treatment in the Ren 2 rats (fig. $1 b$ ).

\section{Enhanced Ang II Generation of Reactive Oxygen \\ Species in the PT Is Mediated through $A T_{1} R$ \\ Activation of NADPH Oxidase in the Transgenic \\ Ren2 Rat}

The NADPH oxidase enzyme complex is an important regulator of Ang II-mediated generation of oxidant stress in the kidney $[17,29]$. Consistent with this notion, there were increases in cortical tissue NADPH oxidase activity (fig. 2a) and PT intensity of subunits Racl and p47 phox $^{\text {in }}$ the Ren 2 rats compared to SD controls. These collective findings improved with telmisartan treatment in the Ren 2 rats (fig. $2 b)$. 


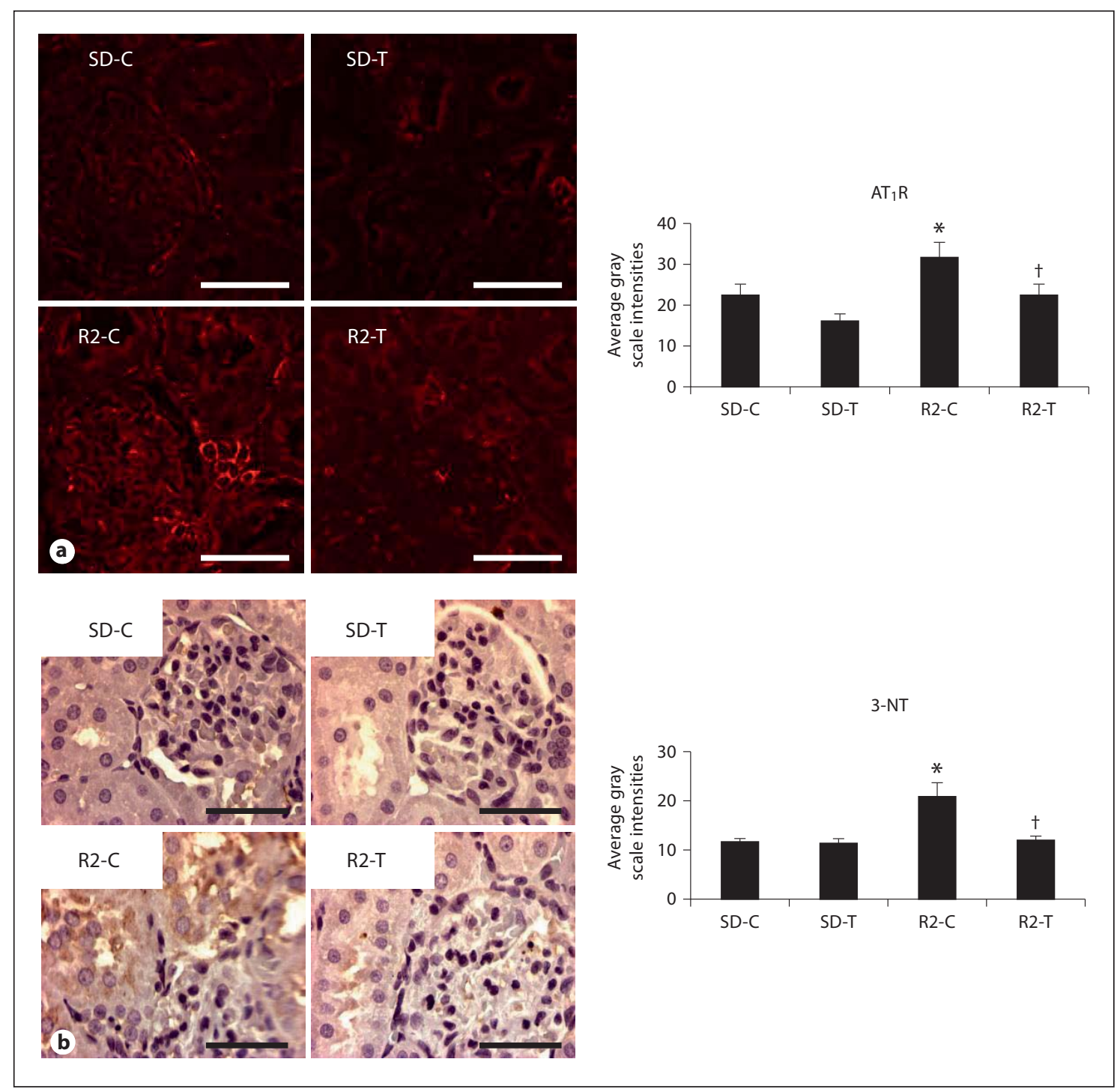

Fig. 1. Angiotensin II contributes to PTC oxidative stress through activation of the $\mathrm{AT}_{1} \mathrm{R}$. a Representative images of semi-quantitative immunohistochemical analysis and localization of the $\mathrm{AT}_{1} \mathrm{R}$ to the $\mathrm{PT}$ with corresponding measures to the right. b Representative images of PT 3-NT content, a marker of peroxynitrite formation $\left(\mathrm{ONOO}^{-}\right)$, with corresponding measures to the right. ${ }^{*} \mathrm{p}<0.05$ when compared to age-matched Sprague-Dawley controls (SD-C); ${ }^{\dagger} \mathrm{p}<0.05$ when telmisartantreated $\mathrm{R} 2$ rats (R2-T) are compared to age-matched Ren 2 controls (R2-C). Scale bar $=50 \mu \mathrm{m}$.
Ang II Contributes to PT Brush Border Injury in the

Transgenic Ren2 Rat

Recent work has highlighted that Ang II contributes directly to PT injury $[16,17,28]$. PTC injury is characterized by release of enzymes such as KIM-1, a marker of brush border injury [30, 31], and neprilysin (e.g. neutral endopeptidase 24.11), an enzyme localized to the brush border and responsible for degrading Ang II [32]. Both are abnormally released from the endosomal brush border region from lysosomes [33]. KIM-1 is upregulated during PT injury, a finding observed in the Ren2 rats compared to SD controls, and improvement was observed with telmisartan treatment in the Ren 2 rats (fig. 3a). Neprilysin is a brush border enzyme which cleaves and downregulates during PT injury. Here, neprilysin decreased in the Ren 2 rats compared to SD controls and showed an improved trend with telmisartan treatment in the Ren 2 rats (fig. $3 b$ ).

PTC brush border injury contributes to reductions in endosomal protein reabsorption. In the Ren 2 rats, there 


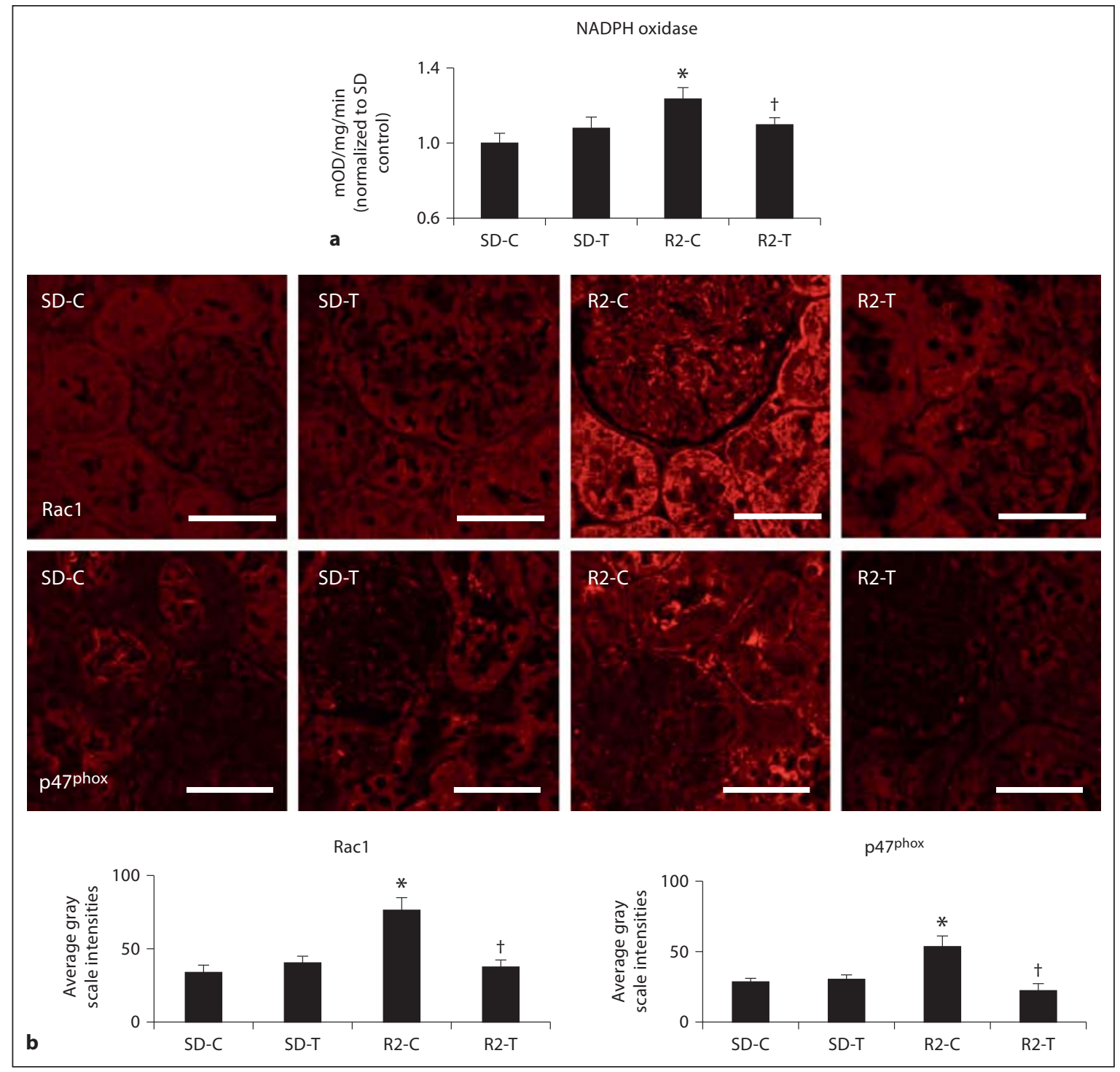

Fig. 2. Angiotensin II activation of PTC NADPH oxidase. a Total NADPH oxidase activity. b Depicts representative images of semi-quantitative immunohistochemistry analysis and localization of NADPH oxidase subunits Racl and p $47^{\text {phox }}$ to the PT with corresponding measures of intensity below. ${ }^{*} \mathrm{p}<0.05$ when compared to age-matched Sprague-Dawley controls (SD-C); ${ }^{\dagger} \mathrm{p}<0.05$ when telmisartan-treated $\mathrm{R} 2$ rats $(\mathrm{R} 2-\mathrm{T})$ are compared to agematched Ren 2 controls (R2-C). Scale bar $=50 \mu \mathrm{m}$. were reductions in PT-specific megalin by semi-quantitative immunohistochemical analysis compared to SD controls, a finding that showed improvement with telmisartan treatment (fig. 3c). These findings were corroborated on ultrastructural analysis of the apical PT wherein there were reductions in clathrin-coated pits, endosomes, and apical vacuoles (arrows) within the endosomal regions of the Ren2 rats compared to SD controls. Similarly, improvement was observed in the telmisartantreated Ren 2 rats (fig. $3 \mathrm{~d}$ ).

Ang II, mTOR, and Tubulointerstitial Fibrosis
Ang II Contributes to Activation of Renal mTOR

Signaling in the Transgenic Ren2 Rat

Recent data highlight an important role for targeting mTOR signaling in tubulointerstitial fibrosis and proteinuria in rodent models of diabetic and polycystic kidney disease [18-20]. Consistent with this notion, there were increases in mTOR and $\mathrm{Ser}^{2448}$ phosphorylation of mTOR (p-mTOR) in the Ren 2 rats compared to SD controls, findings improved with telmisartan treatment (fig. $4 a, b) . ~ S e r^{2448}$ phosphorylation serves as a marker of

Am J Nephrol 2011;34:115-125 


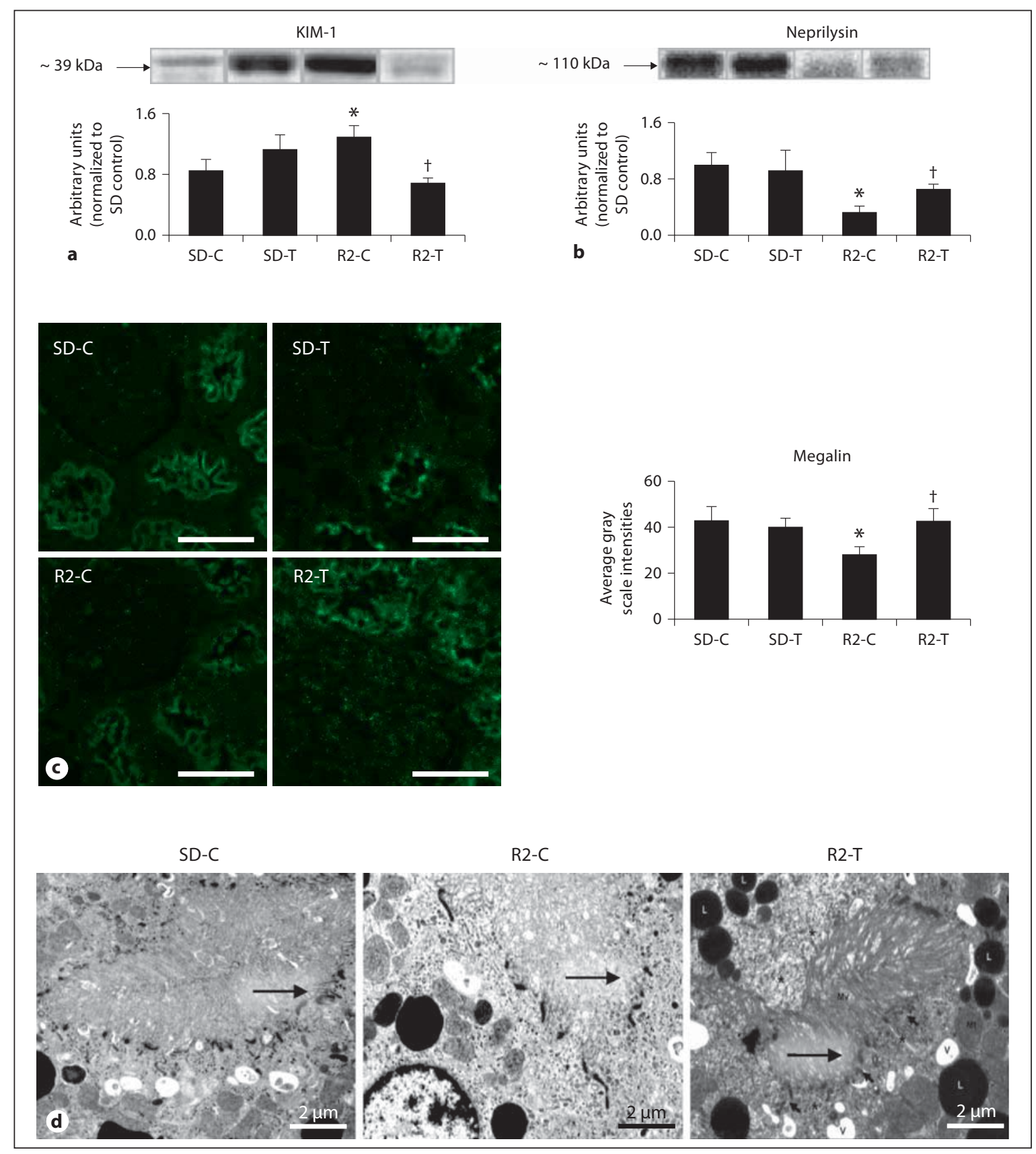

Fig. 3. Angiotensin II contributes to PTC brush border injury. Western blot analysis: a KIM-1, a type 1 membrane protein localized to PT epithelial cells expressed at high levels in human and rodent kidneys after injury, and $\mathbf{b}$ neprilysin (e.g. neutral endopeptidase), a PT brush border enzyme responsible for processing filtered peptides and cleaved during PT injury. c Representative images from semi-quantitative immunohistochemistry analysis of PT-specific megalin with corresponding measures of intensities to the right. Scale bar $=50 \mu \mathrm{m} .{ }^{*} \mathrm{p}<0.05$ when compared to age-matched Sprague-Dawley controls $(\mathrm{SD}-\mathrm{C}) ;{ }^{\dagger} \mathrm{p}<0.05$ when telmisartan-treated $\mathrm{R} 2$ rats (R2-T) are compared to age-matched Ren 2 controls (R2-C). d Ultrastructural analysis of the PTC with TEM. Representative images depict the endosomal region of the Ren 2 control (R2-C) model (middle panel), that demonstrates decreased clathrin-coated pits, endosomes, and apical vacuoles (arrows) compared to the SD-C models (left panel): note that telmisartan treatment in the R2 (R2-T; right panel) restores the alterations compared to the R2-C. 
activation and engagement of the main downstream effector of the mTOR pathway S6K1. In this context, there were concurrent increases in total S6K1 in the Ren2 rats compared to SD controls with an improved trend with telmisartan treatment in the Ren2 rats (fig. 4c).

Ang II Contributes to Loss of Adhesion, PT Basolateral Remodeling, and Tubulointerstitial

Fibrosis in the Transgenic Ren2 Rat

Activation of mTOR/S6K1 contributes to promotion of tubulointerstitial fibrosis and a process characterized by loss of adherens junctions [18-21, 34]. In the Ren 2 rats, there were reductions in the PT-specific $\mathrm{N}$-cadherin compared to SD controls, findings improved with telmisartan treatment in the Ren2 rats (fig. 5a). Consistent with loss of adhesion as a promoter of fibrosis, the loss of PT N-cadherin occurred contemporaneous with increases in tubulointerstitial fibrosis in the Ren 2 rats compared to SD controls, again improved with telmisartan treatment in the Ren 2 rats (fig. 5b).

PT epithelial cell promotion of tubulointerstitial fibrosis may occur through EMT with remodeling of the basilar region and transition of the $\mathrm{PT}$ to a fibroblast phenotype $[1,2,8]$. Early stage EMT is structurally characterized by loss of basal polarity and basement membrane thickening on ultrastructural analysis. In the Ren 2 model, consistent with reductions in endosomal clathrincoated pits, endosomes, and vacuoles (fig. $5 \mathrm{c}$ ), there were reductions in basilar lysosomes (fig. $5 \mathrm{c}$, top panel) with parallel loss in basal polarity (fig. $5 c$, bottom panel). Loss of polarity was manifested by ultrastructural remodeling consisting of mitochondrial fragmentation characterized by loss of elongation and spherical enlargement with mitochondrial matrix abnormalities. Further, there was basement membrane thickening and elongated canalicular plasma membrane infoldings characterized by electron-dense finger-like protrusions along the canaliculi in Ren2 renal tissue, collective findings were not observed in the SD or the telmisartan-treated Ren2 rats.

\section{Discussion}

Results from this investigation support a role for Ang II in eliciting PTC injury and mTOR-associated loss of PTC adhesion and tubulointerstitial fibrosis. Our current observations extend evidence in smooth muscle cells, cardiac tissue, and skeletal muscle cells that Ang II engages mTOR/ S6K1 through a PI3-K/Akt-dependent pathway [8, 11-13]. Herein, we report that in the transgenic Ren2 model, a model of increased tissue Ang II and proteinuria, there were increases in renal tissue levels of NADPH oxidase and dependent increases in reactive oxygen species (ROS). Furthermore, it also displayed PT brush border injury with increases in KIM-1 and reductions in neprilysin with parallel increases in p-mTOR, mTOR and S6K1. Contemporaneous with these findings, there were associated reductions in the PT-specific adhesion molecule $\mathrm{N}$-cadherin and ultrastructural findings of PT remodeling consistent with EMT and tubulointerstitial fibrosis. Collectively, our findings were largely improved with $\mathrm{AT}_{1} \mathrm{R}$ blockade, supporting a role for $\mathrm{AT}_{1} \mathrm{R}$-mediated signaling through mTOR/S6K1 in PT injury and tubulointerstitial fibrosis.

Blockade of the $\mathrm{AT}_{1} \mathrm{R}$ reduces NADPH oxidase activity and the Nox subunit Racl, a small GTP-ase [10, 14, 15]. Racl is a critical G-protein that not only contributes to activation of the enzyme complex NADPH oxidase and generation of oxidative stress in PT cells, but also functions as an important regulator of endocytosis of albumin in the PT $[17,35]$. Our finding that $\mathrm{AT}_{1} \mathrm{R}$ blockade reduced subunits Rac1, p47 $7^{\text {phox }}$ and NADPH oxidase-dependent generation of 3-NT in the Ren2 further supports a role for Ang II engagement in NADPH oxidase generation of oxidant stress in the PT.

Recent data also highlight a potential role for Ang II in regulating the mTOR pathway and in PT albumin endocytosis that is mediated, in part, via regulation of megalin $[11-13,35,36]$. Megalin is involved in albumin reabsorption through a retrieval mechanism wherein albumin is transported through an endosomal/lysosomal degradation pathway and degraded into its constituent polypeptides and amino acids [37, 38]. In this context, our data extend findings from PT culture models in recent studies $[17,35]$ into an in vivo model (e.g. the Ren2), where Ang II-dependent signaling through the $\mathrm{AT}_{1} \mathrm{R}$ reduces megalin expression that occurs in conjunction with ultrastructural findings of reduced endosomal lysosomes and increases in proteinuria $[25,35,37-39]$. Although the exact mechanism remains unclear, our data would suggest that this reduction in megalin expression may be mediated, in part, through an $\mathrm{AT}_{1} \mathrm{R}$-dependent signaling pathway.

In this investigation, renal cortical KIM-1 levels were increased in Ren2 rats and normalized with $\mathrm{AT}_{1} \mathrm{R}$ blockade. Although KIM-1 was originally described to be induced in the post-ischemic kidney, tubular KIM-1 induction has also been reported recently in models of proteinuric and polycystic kidney disease [28, 30]. Recent data suggest that KIM-1 expression is increased in the Ren 2 rats and attenuated following treatment with $\mathrm{AT}_{1} \mathrm{R}$ blockade or mitogen-activated protein kinase inhibition [28]. This is a 


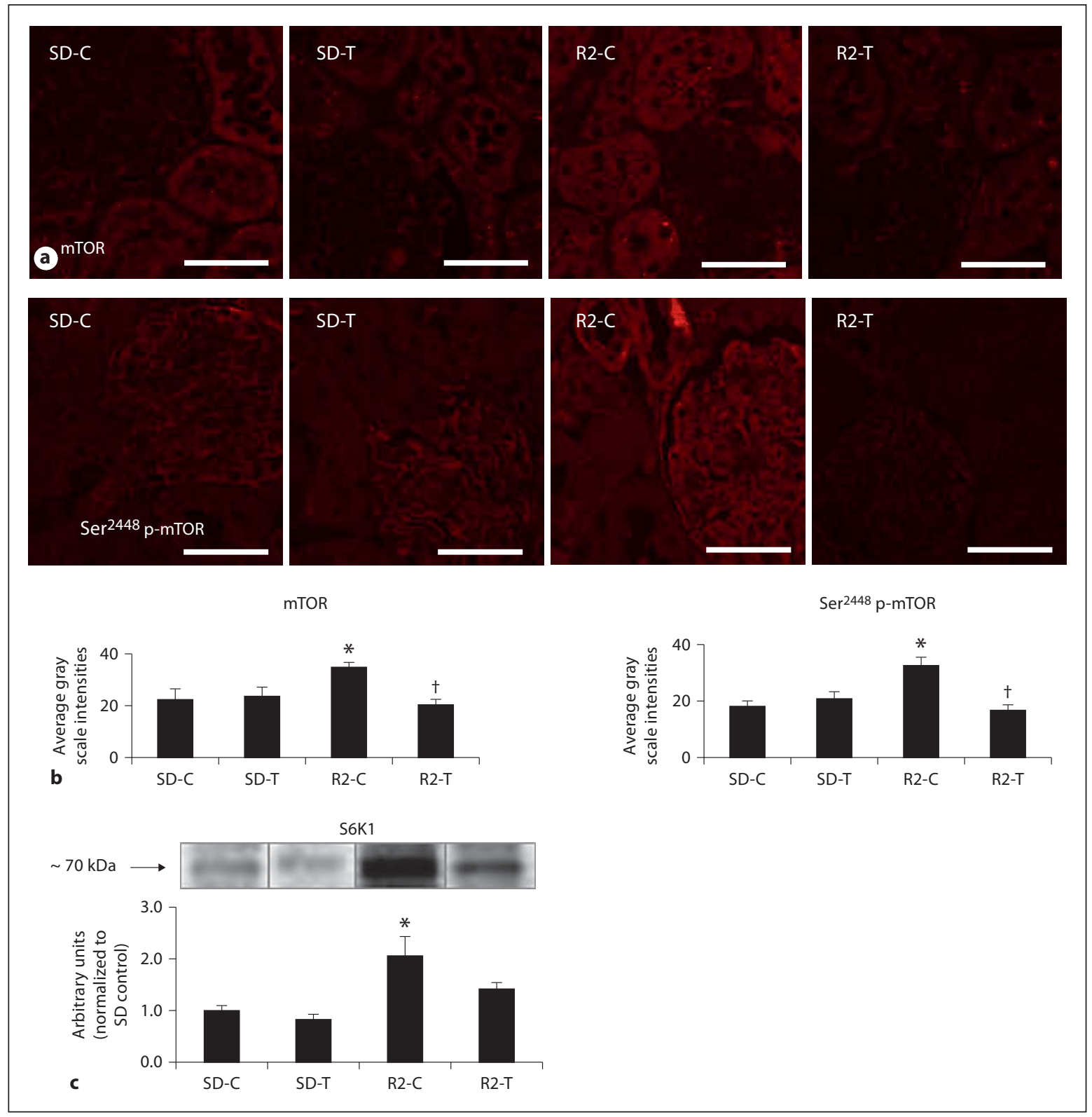

Fig. 4. Angiotensin II contributes to activation of PTC mTOR signaling. $\mathbf{a}, \mathbf{b}$ Representative images from semi-quantitative immunohistochemistry analysis and localization of PT mTOR and $\mathrm{Ser}^{2448}$ p-mTOR with corresponding intensities below. Scale bar $=50 \mu \mathrm{m}$. c Western blot analysis of S6K1 the main effector peptide of mTOR. ${ }^{*} \mathrm{p}<0.05$ when compared to age-matched SpragueDawley controls (SD-C); ${ }^{\dagger} \mathrm{p}<0.05$ when telmisartan-treated R2 rats (R2-T) are compared to age-matched Ren2 controls (R2-C). particularly important finding in that mitogen-activated protein kinase is known to converge with mTOR signaling through phosphorylation of S6K1. Our data further highlight a role for Ang II in PT injury as the observed improvement in KIM-1 following $\mathrm{AT}_{1} \mathrm{R}$ blockade was temporally related to increases in neprilysin (e.g. neutral endopeptidase), a brush border enzyme responsible for processing peptides, such as Ang II, that is reduced during injury to the PT [33]. Our collective findings suggest that increased KIM-1 and reduced neprilysin expression represent markers of brush border injury and targets for Ang II-dependent generation of ROS and altered mTOR/S6K1 signaling in PT injury.

Targeting reductions in mTOR/S6K1 activity with rapamycin treatment improves tubulointerstitial fibrosis and proteinuria in rodent models of diabetic nephropa- 


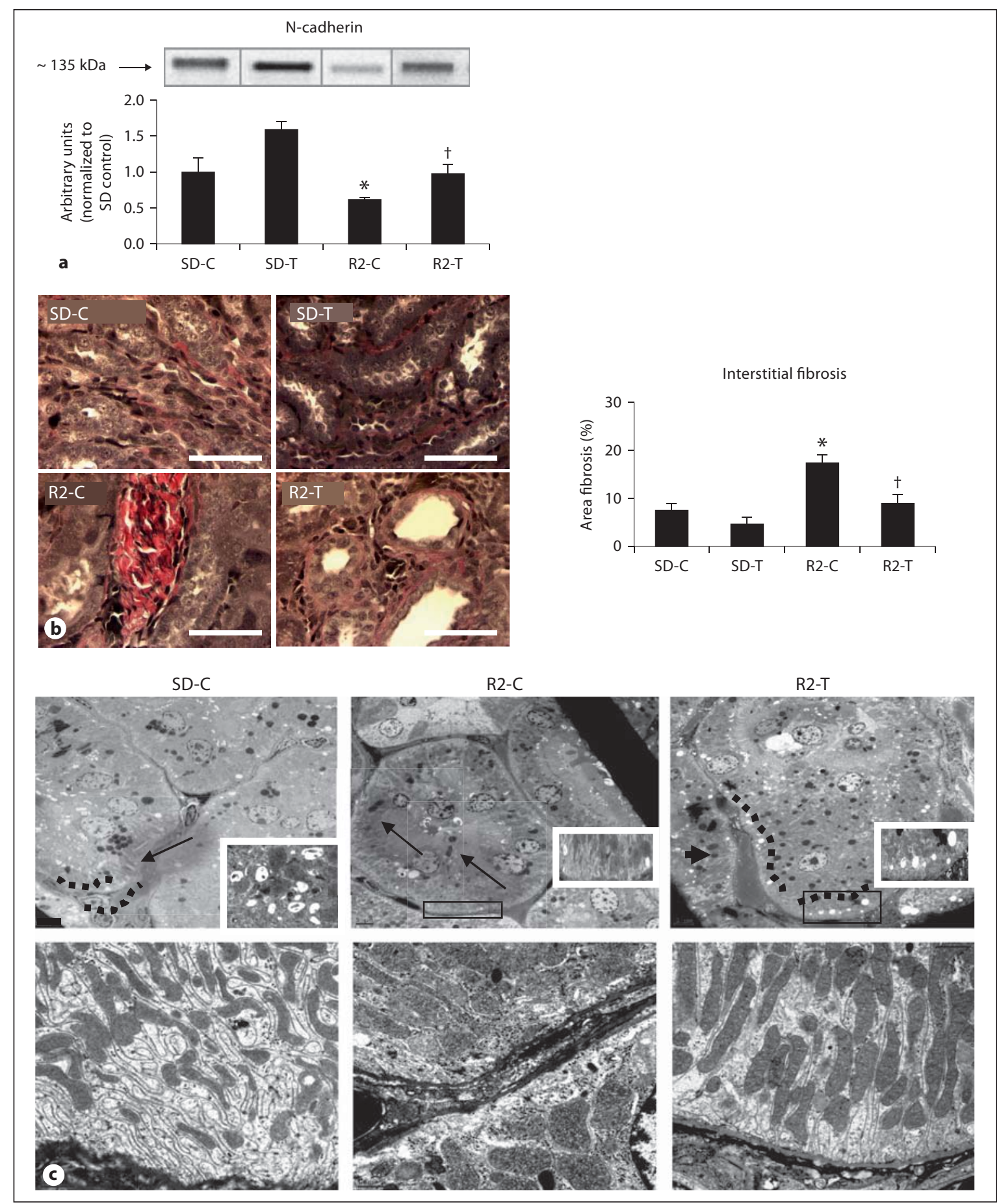

Fig. 5. Angiotensin II contributes to loss of PT N-cadherin, basolateral remodeling and tubulointerstitial fibrosis. a Western blot analysis of the PT-specific adhesion molecule $\mathrm{N}$-cadherin. b Verhoeff-Van Gieson (VVG) stain for elastin and collagen with measures of tubulointerstitial fibrosis to the right. Scale bar 50 $\mu \mathrm{m} .{ }^{*} \mathrm{p}<0.05$ when compared to age-matched Sprague-Dawley controls (SD-C); ${ }^{\dagger} \mathrm{p}<0.05$ when telmisartan-treated $\mathrm{R} 2$ rats (R2$\mathrm{T})$ are compared to age-matched Ren 2 controls (R2-C). c Representative images from ultrastructural analysis of TEM for the S-1 region of the PT. Top panel depicts lysosomes in the basal region of the PT wherein there is loss of electron dense lysosome (arrows) in the R2-C model (middle panel) compared to agematched SD-C, restored with telmisartan treatment in the Ren2. Bottom panel depicts elongated canalicular plasma membrane infoldings, loss of basal polarity, elongated mitochondria and basement membrane thickening in the basal region of the $\mathrm{R} 2-\mathrm{C}$ compared to SD-C, findings improved in the telmisartan-treated R2 model. 
thy and polycystic kidney disease [18-20]. The activity of mTOR appears to be highly regulated under conditions of high nutrient/energy levels, hypoxia, or various hormones such as Ang II, as suggested by our study, which allow mTOR kinase activity to be turned on promoting cell phenotype transition and fibrosis. $\mathrm{Ser}^{2448} \mathrm{p}$-mTOR serves as a marker for downstream activation of $\mathrm{S} 6 \mathrm{~K} 1$ as well as mTOR inhibition. While our study did not include a direct inhibitor of $\mathrm{Ser}^{2448}$ p-mTOR such as rapamycin, our finding that blockade of the $\mathrm{AT}_{1} \mathrm{R}$ in this transgenic RAS model inhibits total and $\operatorname{Ser}^{2448}$ phosphorylated mTOR further support a role for Ang II in mTOR/S6K1 signaling in the kidney.

Our observation that $\mathrm{AT}_{1} \mathrm{R}$ blockade in the Ren2 rat also led to improvements in tubulointerstitial fibrosis temporally related to improvements in p-mTOR further support a role for Ang II in fibrosis. Ang II actions on the $\mathrm{AT}_{1} \mathrm{R}$ have been shown to regulate collagen synthesis and extracellular matrix protein synthesis as well as through generation of ROS $[29,40,41]$. Under steady state conditions, PTCs are attached to each other and to the basement membrane through specialized junctional complexes (adherens junctions) that are susceptible to ROS and include molecules such as cadherin. Recent data suggest that the cadherin present in the kidney $[23,24]$ and specific to the PT is N-cadherin [23]. N-cadherin in the PT has been shown to bind cytoskeletal components that provide a structural foundation for adherens junctions. Of note, cadherins not only function as static structural components of adherens junctions but also play a role in cell-signaling pathways [42] suggesting that cadherins may be a target of Ang II and mTOR signaling. Our finding that $\mathrm{AT}_{1} \mathrm{R}$ blockade improves the $\mathrm{PT}$-specific $\mathrm{N}$-cadherin in the Ren2, support a role for Ang II activation of mTOR/S6K1 and loss of $\mathrm{N}$-cadherin in association with EMT and tubulointerstitial fibrosis.

Recent evidence suggests EMT as a potential initial mechanism for tubulointerstitial fibrosis in human and other species $[1,2,8]$. Our findings that loss of N-cad- herin occurred contemporaneous with ultrastructural remodeling of the basilar region of the $\mathrm{PT}$ in the Ren 2 rats is consistent with structural changes of EMT and fibrosis. The finding that these changes were improved with $\mathrm{AT}_{1} \mathrm{R}$ blockade supports a potential role for Ang II. Although our findings are ultrastructural in nature and not related to the alterations in EMT transcriptome. Ultrastructural changes of early-stage EMT are characterized by loss of basal polarity and basement membrane thickening on ultrastructural analysis $[2,25,42]$. Our observations in the Ren 2 kidney of reductions in basilar lysosomes with parallel loss in basal polarity, mitochondrial fragmentation, basement membrane thickening and canalicular infoldings of the plasma membrane with improvements following $\mathrm{AT}_{1} \mathrm{R}$ blockade support a direct role for Ang II actions on loss of $\mathrm{N}$-cadherin and promotion of structural changes consistent with EMT and tubulointerstitial fibrosis.

Thereby, this preclinical investigation highlights a novel mechanism in eliciting tubulointerstitial fibrosis. The clinical/translational importance of our study resides in the identification of an $\mathrm{AT}_{1} \mathrm{R}$-mediated mechanism at an early juncture in the development of tubulointerstitial fibrosis, a process the dictates progressive kidney disease.

\section{Acknowledgments}

The authors would like to acknowledge the excellent support of Nathan Rehmer, Rebecca I. Schneider, and Mona Garro for their help in conducting the studies as well as Charles Wiedmeyer in performing the measures of proteinuria. The authors would also like to acknowledge the support of the Electron Microscopy Core.

This research was supported by NIH R01 HL-73101 to J.R.S. and HL-51952 to C.M.F and RO1 AG-034154 to A.R.P., and Veterans Affairs Merit System (0018) for J.R.S. as well as CDA-2 (A.W.-C.), and Boehringer Ingelheim Pharmaceuticals.

\section{Disclosure Statement}

The authors have no conflicts of interest to disclose.

\section{References}

Eddy AA: Progression in chronic kidney disease. Adv Chronic Kidney Dis 2005; 12:353-365.

2 Rodríguez-Iturbe B, García García G: The role of tubulointerstitial inflammation in the progression of chronic renal failure. Nephron Clin Pract 2010;116:c81-c88.

- 3 Fujii H, Kono K, Nakai K, Goto S, Komaba H, Hamada Y, Shinohara M, Kitazawa R, Kitazawa S, Fukagawa M: Oxidative and nitrosative stress and progression of diabetic nephropathy in type 2 diabetes. Am J Nephrol 2010;31:342-352.

-4 Okada H, Kalluri R: Cellular and molecular pathways that lead to progression and regression of renal fibrogenesis. Curr Mol Med 2005;5:467-474.

2005;5:467-474.
Sowers JR: Metabolic risk factors and renal disease. Kidney Int 2007;71:719-720.

-6 Gonzalez-Villalobos RA, Seth DM, Satou R, Horton H, Ohashi N, Miyata K, Katsurada A,
Tran DV, Kobori H, Navar LG: Intrarenal angiotensin II and angiotensinogen augmentation in chronic angiotensin II-infused mice. Am J Physiol Renal Physiol 2008;295:F772F779.

7 Yang F, Huang XR, Chung AC, Hou CC, Lai KN, Lan HY: Essential role of Smad3 in angiotensin II-induced tubular epithelial-mesenchymal transition. J Pathol 2010;221:390401. 
${ }_{8}$ Jinde K, Nikolic-Paterson DJ, Huang XR, Sakai H, Kurokawa K, Atkins RC, Lan HY: Tubular phenotypic change in progressive tubulointerstitial fibrosis in human glomerulonephritis. Am J Kidney Dis 2001;38:761769.

-9 Bakris G, Burgess E, Weir M, Davidai G, Koval S: AMADEO Study Investigators: Telmisartan is more effective than losartan in reducing proteinuria in patients with diabetic nephropathy. Kidney Int 2008;74:364-369.

10 Kalaitzidis R, Bakris GL: Effects of angiotensin II receptor blockers on diabetic nephropathy. J Hypertens 2009;27:S15-S21.

-11 Chiu T, Santiskulvong C, Rozengurt E: 2EGF receptor transactivation mediates ANG IIstimulated mitogenesis in intestinal epithelial cells through the PI3-kinase/Akt/mTOR/ p70S6K1 signaling pathway. Am J Physiol Gastrointest Liver Physiol 2005;288:G182G194.

-12 Diniz GP, Carneiro-Ramos MS, BarretoChaves ML: Angiotensin type 1 receptor mediates thyroid hormone-induced cardiomyocyte hypertrophy through the Akt/GSK3beta/mTOR signaling pathway. Basic Res Cardiol 2009; 104:653-667.

13 Hafizi S, Wang X, Chester AH, Yacoub MH, Proud CG: Ang II activates effectors of mTOR via PI3-K signaling in human coronary smooth muscle cells. Am J Physiol Heart Circ Physiol 2004;287:H1232-H1238.

- 14 Gorin Y, Ricono JM, Kim NH, Bhandari B, Choudhury GG, Abboud HE: Nox4 mediates angiotensin II-induced activation of Akt/ protein kinase B in mesangial cells. Am J Physiol Renal Physiol 2003;285:F219-F229.

-15 Hingtgen SD, Tian X, Yang J, Dunlay SM, Peek AS, Wu Y, Sharma RV, Engelhardt JF, Davisson RL: Nox2-containing NADPH oxidase and Akt activation play a key role in angiotensin II-induced cardiomyocyte hypertrophy. Physiol Genomics 2006;26:180-191.

$\checkmark 16$ Hayden MR, Chowdhury NA, Cooper SA, Whaley-Connell A, Habibi J, Witte L, Wiedmeyer C, Manrique CM, Lastra G, Ferrario C, Stump C, Sowers JR: Proximal tubule microvilli remodeling and albuminuria in the Ren2 transgenic rat. Am J Physiol Renal Physiol 2007;292:F861-F867.

-17 Whaley-Connell AT, Morris EM, Rehmer N, Yaghoubian JC, Wei Y, Hayden MR, Habibi J, Stump CS, Sowers JR: Albumin activation of $\mathrm{NAD}(\mathrm{P}) \mathrm{H}$ oxidase activity is mediated via Racl in proximal tubule cells. Am J Nephrol 2007;27:15-23.

18 Lieberthal W, Levine JS: The role of the mammalian target of rapamycin (mTOR) in renal disease. J Am Soc Nephrol 2009;20: 2493-2502.

19 Lloberas N, Cruzado JM, Franquesa M, Herrero-Fresneda I, Torras J, Alperovich G, Rama I, Vidal A, Grinyo JM: Mammalian target of rapamycin pathway blockade slows progression of diabetic kidney disease in rats. J Am Soc Nephrol 2006;17:13951404.
20 Tao Y, Kim J, Schrier RW, Edelstein CL: Rapamycin markedly slows disease progression in a rat model of polycystic kidney disease. J Am Soc Nephrol 2005;16:46-51.

21 Barnes EA, Kenerson HL, Jiang X, Yeung RS: Tuberin regulates E-cadherin localization: implications in epithelial-mesenchymal transition. Am J Pathol 2010;177:1765-1778.

22 Bieri M, Oroszlan M, Zuppinger C, Mohacsi PJ: Biosynthesis and expression of VE-cadherin is regulated by the PI3K/mTOR signaling pathway. Mol Immunol 2009;46:866-872.

23 Jung KY, Dean D, Jiang J, Gaylor S, Griffith WH, Burghardt RC, Parrish AR: Loss of Ncadherin and alpha-catenin in the proximal tubules of aging male Fischer 344 rats. Mech Ageing Dev 2004;125:445-453.

24 Kreidberg JA, Symons JM: Integrins in kidney development, function, and disease. Am J Physiol Renal Physiol 2000;279:F233-F242.

25 Hayden MR, Habibi J, Whaley-Connell A, Sowers D, Johnson MS, Tilmon R, Jain D, Ferrario C, Sowers JR: Nebivolol attenuates maladaptive proximal tubule remodeling in transgenic rats. Am J Nephrol 2010;31:262272.

26 DeMarco VG, Johnson MS, Habibi J, Pulakat L, Gul R, Hayden MR, Tilmon R, Dellsperger KC, Winer N, Whaley-Connell AT, Sowers. JR: Comparative analysis of telmisartan and olmesartan on cardiac function in the TG(mRen2)27 rat. Am J Physiol Heart Circ Physiol 2011;300:H181-H190.

27 Arozal W, Watanabe K, Veeraveedu PT, Ma M, Thandavarayan RA, Sukumaran V, Suzuki K, Kodama M, Aizawa Y: Telmisartan prevents the progression of renal injury in daunorubicin rats with the alteration of angiotensin II and endothelin-1 receptor expression associated with its PPAR- $\gamma$ agonist actions. Toxicology 2011;279:91-99.

-28 de Borst MH, van Timmeren MM, Vaidya VS, de Boer RA, van Dalen MB, Kramer AB, Schuurs TA, Bonventre JV, Navis G, van Goor H: Induction of kidney injury molecule-1 in homozygous Ren 2 rats is attenuated by blockade of the renin-angiotensin system or p38 MAP kinase. Am J Physiol Renal Physiol 2007;292:F313-F320.

29 Nistala R, Whaley-Connell A, Sowers JR: Redox control of renal function and hypertension. Antioxid Redox Signal 2008;10:20472089.

30 Ichimura T, Asseldonk EJ, Humphreys BD, Gunaratnam L, Duffield JS, Bonventre JV: Kidney injury molecule- 1 is a phosphatidylserine receptor that confers a phagocytic phenotype on epithelial cells. J Clin Invest 2008;118:1657-1668.

-31 Nishihara K, Masuda S, Nakagawa S, Yonezawa $\mathrm{A}$, Ichimura $\mathrm{T}$, Bonventre $\mathrm{JV}$, Inui $\mathrm{K}$ : Impact of Cyclin B2 and cell division cycle 2 on tubular hyperplasia in progressive chronic renal failure rats. Am J Physiol Renal Physiol 2010;298:F923-F934.

-32 Ferrario CM, Averill DB, Brosnihan KB, Chappell MC, Iskandar SS, Dean RH, Diz
DI. Vasopeptidase inhibition and Ang-(1-7) in the spontaneously hypertensive rat. Kidney Int 2002;62:1349-1357.

33 Lebeau C, Debelle FD, Arlt VM, Pozdzik A, De Prez EG, Phillips DH, Deschodt-Lanckman MM, Vanherweghem JL, Nortier JL: Early proximal tubule injury in experimental aristolochic acid nephropathy: functional and histological studies. Nephrol Dial Transplant 2005;20:2321-2332.

34 Loverre A, Ditonno P, Crovace A, Gesualdo L, Ranieri E, Pontrelli P, Stallone G, Infante B, Schena A, Di Paolo S, Capobianco C, Ursi M, Palazzo S, Battaglia M, Selvaggi FP, Schena FP, Grandaliano G: Ischemia-reperfusion induces glomerular and tubular activation of proinflammatory and antiapoptotic pathways: differential modulation by rapamycin. J Am Soc Nephrol 2004;15:2675-2686.

35 Hosojima M, Sato H, Yamamoto K, Kaseda R, Soma T, Kobayashi A, Suzuki A, Kabasawa $\mathrm{H}$, Takeyama A, Ikuyama $\mathrm{K}$, Iino $\mathrm{N}$, Nishiyama A, Thekkumkara TJ, Takeda T, Suzuki Y, Gejyo F, Saito A: Regulation of megalin expression in cultured proximal tubule cells by angiotensin II type 1 A receptorand insulin mediated signaling cross talk. Endocrinology 2009;150:871-878.

36 Oroszlán M, Bieri M, Ligeti N, Farkas A, Meier B, Marti HP, Mohacsi P: Sirolimus and everolimus reduce albumin endocytosis in proximal tubule cells via an angiotensin IIdependent pathway. Transpl Immunol 2010; 23:125-132.

37 Verroust PJ, Birn H, Nielsen R, Kozyraki R, Christensen EI: The tandem endocytic receptors megalin and cubilin are important proteins in renal pathology. Kidney Int 2002; 62:745-756

38 Lamaze C, Chaung TH, Terlecky LJ, Bokoch GM, Schmid SL: Regulation of receptor-mediated endocytosis by Rho and Rac. Nature 2006;382:177-179.

39 Li XC, Carretero OA, Navar LG, Zhuo JL: $\mathrm{AT}_{1}$ receptor-mediated accumulation of extracellular angiotensin II in proximal tubule cells: role of cytoskeleton microtubules and tyrosine phosphatases. Am J Physiol Renal Physiol 2006;291:F375-F383.

40 Van Timmeren MM, Bakker SJ, Vaidya VS, Bailly V, Schuurs TA, Damman J, Stegeman CA, Bonventre JV, Van Goor H: Tubular kidney injury molecule-1 (Kim-1) in proteinoverload nephropathy. Am J Physiol Renal Physiol 2006;291:F456-F464.

$41 \mathrm{Ha} \mathrm{H}$, Lee HB: Reactive oxygen species and matrix remodeling in diabetic kidney. J Am Soc Nephrol 2003;14:S246-S249.

42 Strutz F, Zeisberg M, Ziyadeh FN, Yang CQ, Kalluri R, Müller GA, Neilson EG: Role of basic fibroblast growth factor-2 in epithelialmesenchymal transformation. Kidney Int 2002;61:1714-1728

43 Lee JM, Dedhar S, Kalluri R, Thompson EW: The epithelial-mesenchymal transition: new insights in signalling, development, and disease. J Cell Biol 2006;172:973-981. 